\title{
Sistema tributario aduanero peruano y beneficios de los acuerdos de integración comercial Perú-México
}

\section{The Peruvian Customs Tax System and the Benefits from the Trade Integration Agreements Between Peru-México}

Marco Antonio Huamán Sialer*

http://dx.doi.org/10.21503/lex.v16i22.1658

* Postdoctor con mención en Producción Científica. Ph. D. con mención en Estudios Legales Internacionales por la Atlantic International University, Estados Unidos de Norteamérica. Doctor en Derecho. Doctor en Educación por la Universidad Nacional Mayor de San Marcos. Máster en Aduanas. Especialista en Aduanas por la Escuela Nacional de Aduanas, hoy Instituto Aduanero y Tributario (IAT). Postgrado en Tributos Internos por la Universidad de Lima. Profesor de Postgrado en la UNMSM, PUCP, ESAN, U de Lima, U Federico Villarreal, UNI y UAP. Actual vocal presidente de la Sala de Aduanas del Tribunal Fiscal. Presidente de la Asociación Peruana de Derecho Aduanero y Comercio Internacional (APDACI). Miembro de la Academia Internacional de Derecho Aduanero. Socio del IPDT.

Correo electrónico: mhuaman@mef.gob.pe; m_huaman@doc.uap.edu.pe

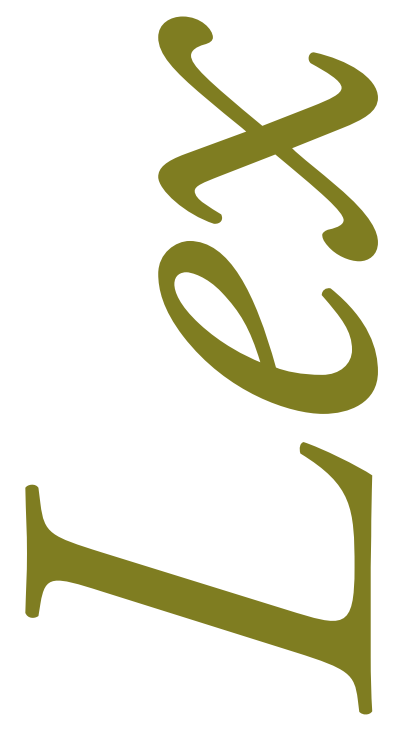




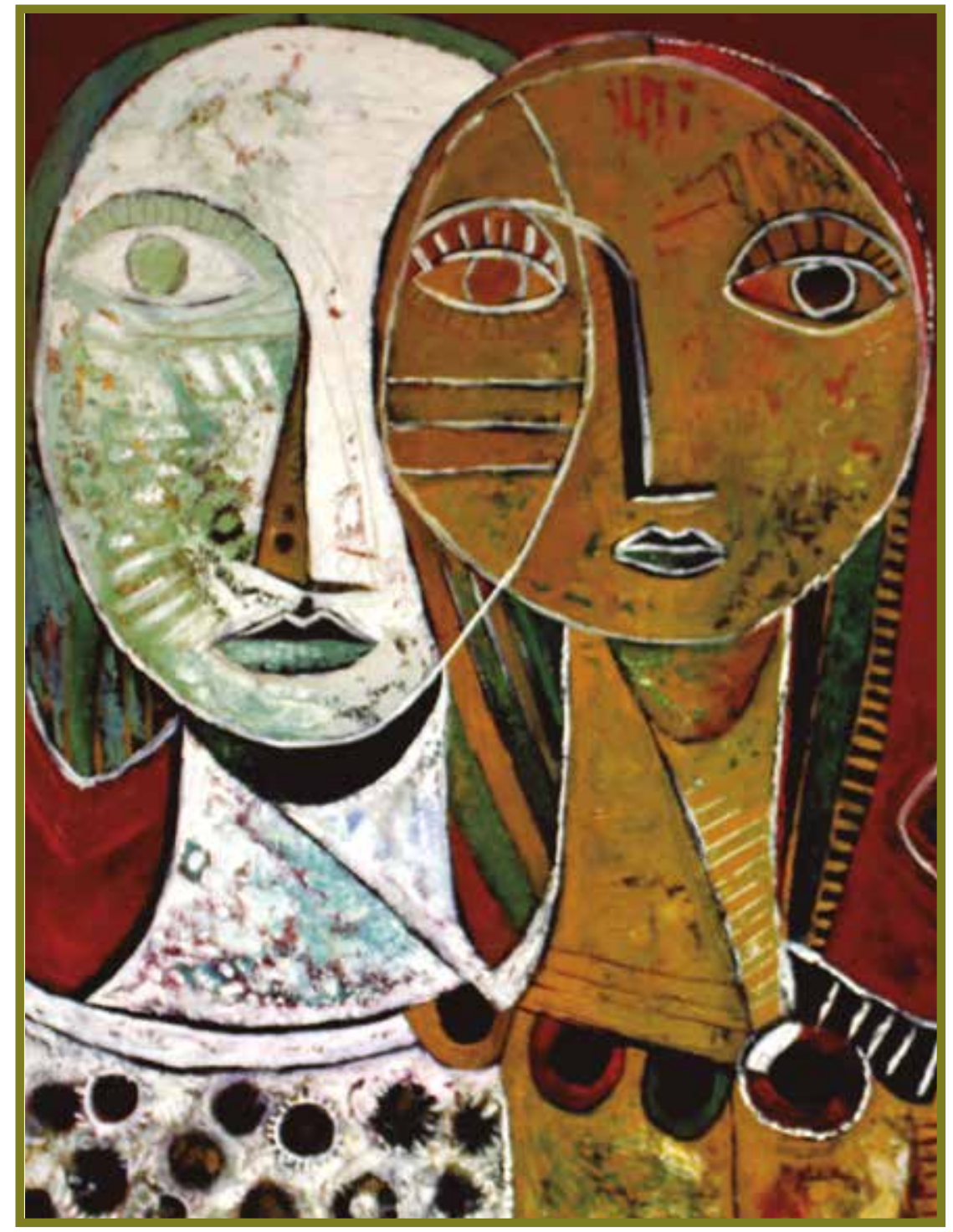

Juntos. Pinturas. Juan Carlos Nananake. 


\section{RESUMEN}

El presente artículo analiza el Sistema Tributario Aduanero del Perú, para lo cual se inicia con una breve reseña de la base legal que rige la normatividad interna, para luego señalar y definir cada uno de los tributos aduaneros que se pagan en el comercio exterior. Luego se comentaran los aspectos más importantes de los Acuerdos de Integración Comercial que el Perú ha suscrito con México, partiendo por sus antecedentes, los beneficios tributarios arancelarios y el actual flujo comercial de las mercancías (estadísticas) del Acuerdo de Integración Comercial Perú-México y el Acuerdo de Alianza del Pacífico Perú, México, Colombia y Chile; asimismo se comentara la casuística emitida por el Tribunal Fiscal de Perú en materia de acogimiento del Tratado de Libre Comercio (TLC) entre Perú y México, para finalmente llegar a señalar las conclusiones respectivas.

Palabras clave: Sistema Tributario Aduanero, Ley General de Aduanas, arancel de aduanas, tributos aduaneros, acuerdo comercial, Tratado de Libre Comercio, categorias de desgravación, flujo comercial, resolución del Tribunal Fiscal.

\section{ABSTRACT}

This article analyzes the Customs Tax System of Peru, starting with a brief review of the legal basis that governs domestic regulations, afterwards appointing and defining each of the Customs Taxes paid in foreign trade, commenting the key aspects of the Trade Integration Agreements signed between Peru and Mexico, such as their background, tariff benefits and the current commercial flow of goods (statistics) from the Peru-Mexico Trade Integration Agreement and from the Pacific Alliance Agreement involving Peru, Mexico, Colombia and Chile. In addition, this article comments about cases solved by the Tax Peruvian Tax Court regarding the application of the Free Trade Agreement (FTA) between Peru and Mexico to end with the corresponding conclusions.

Key words: Customs Tax System, General Customs Law, customs tariff, customs taxes, commercial agreement, Free Trade Agreement, categories of tax relief, commercial flow, Tax Court resolutio. 


\section{INTRODUCCIÓN}

La política de Comercio Exterior de Perú desde la década de los ańos 90 en adelante se ha caracterizado por la apertura comercial con el resto de países del mundo, siendo que en el año 2008 con la promulgación de la nueva Ley General de Aduanas aprobada por Decreto Legislativo No 1053 se dio inicio al gran cambio en el comercio exterior, pues la legislación interna peruana se tuvo que adaptar a la apertura comercial, con la finalidad de aplicar el principio de facilitación de comercio exterior en todo el proceso de importación y exportación de mercancías. Es así que la tendencia a futuro es que el derecho ad/valorem (pago de tributo por importar mercancías) vaya de manera progresiva desapareciendo, es decir que llegue a ser $0 \%$ para todas las subpartidas nacionales que se consignan en el arancel de Aduanas. Actualmente la estructura arancelaria en el Perú representa una desgravación de 5497 subpartidas nacionales con $0 \% \mathrm{de}$ ad/valorem, es decir casi el $70,45 \%$ de todas las subpartidas nacionales no pagan derechos ad/valorem. Como se puede apreciar, la tendencia es que los derechos ad/ valorem lleguen a $0 \%$ para todas la subpartidas nacionales, pero ello no implica que cada país de manera interna disponga la aplicación de otros tributos aduaneros a la importación, como son el Impuesto General a las Ventas (IGV) o llamado en otros países como el Impuesto al Valor Agregado (IVA). También tenemos el Impuesto Selectivo al Consumo (ISC), entre otros tributos, mediante los cuales se busca una efectiva recaudación tributaria aduanera a fin de contribuir con el desarrollo económico del país.

Es por ello, que la apertura comercial trae como consecuencia que el Perú tenga un mayor grado de competitividad a nivel internacional y estreche lazos comerciales con distintos países, convirtiéndose en sus socios comerciales, es así que uno de los principales socios comerciales que tiene el Perú es el país de México, con quien tiene suscrito un Acuerdo de Integración Comercial ${ }^{1}$ Perú-México y un Acuerdo de Alianza del Pacífico Perú, México, Colombia y Chile; por tanto, según la estadística proporcionada por el Ministerio de Comercio Exterior y Turismo entre enero y marzo del 2017, las exportaciones no tradicionales dirigidas a México

1 También llamado Tratado de Libre Comercio (TLC). 
alcanzaron un valor de US\$ 61,3 millones (-3,4 \%), representando el 2,3\% de las exportaciones no tradicionales enviadas al mundo. Asimismo, la Alianza del Pacífico es el segundo bloque comercial más importante de América después del NAFTA. Es así que en el año 2016, el intercambio comercial de la integración superó el billón de dólares, valor equivalente a 2,1 veces el comercio del Mercosur. Perú, Chile y Colombia producen y exportan principalmente minerales (cobre, oro) y productos agroindustriales (café, manzanas, uvas, vinos, espárragos), mientras que México exporta mayormente productos metalmecánicos (automóviles, máquinas automáticas y partes de teléfono). El comercio intra Alianza del Pacífico representa para Perú casi la décima parte de su comercio total. En el primer semestre de 2017, el valor del comercio creció $8,4 \%$ respecto a similar período de 2016, pudiendo superar los US\$ 6500 millones en 2017. Perú exporta principalmente productos no tradicionales, y compra televisores, vehículos, petróleo y azúcar.

Como se puede apreciar, las estadísticas vienen demostrando que los acuerdos comerciales sí tienen un impacto positivo en el desarrollo económico de los países, pues permite la exportación de productos no tradicionales y se complementan con la importación de bienes de capital e infraestructura, además de desarrollo tecnológico, que permiten el crecimiento sostenible de las industrias y sectores económicos del país.

\section{BASE LEGAL}

De acuerdo a la legislación aduanera vigente en el Perú, el Sistema Tributario Aduanero se encuentra amparado en primer lugar, por la Ley General de Aduanas aprobada por Decreto Legislativo No 1053 publicada en el Diario Oficial El Peruano el 27 de junio de 2008, la cual entró en vigencia de manera progresiva, alcanzado su plena vigencia el 01 de octubre de 2010, siendo la sección sexta la que regula el régimen tributario aduanero, desde el artículo $139^{\circ} \mathrm{al}$ $161^{\circ}$, en los cuales se regulan los sujetos, el nacimiento, la determinación, la exigibilidad y la extinción de la obligación tributaria aduanera, así como las devoluciones por pagos indebidos o en exceso y las garantías aduaneras vinculadas al pago de los tributos aduaneros.

Dicha Ley General de Aduanas es complementada con su Reglamento aprobado por Decreto Supremo No 010-2009-EF publicado en el Diario Oficial El Peruano el 16 de enero de 2009, alcanzando también su plena vigencia el 01 de octubre de 2010, siendo su sección sexta la que regula el régimen tributario aduanero, desde el artículo $202^{\circ}$ al $222^{\circ}$.

Además, se tiene al arancel de Aduanas aprobado por Decreto Supremo No 342-2016-EF publicado en el Diario Oficial El Peruano el 16 de diciembre de 2016, puesto en vigencia el 01 de enero de 2017, siendo que el arancel de Aduanas del Perú ha sido elaborado en base a la Nomenclatura Común de los Países Miembros de la Comunidad Andina (NANDINA), con la inclusión de subpartidas nacionales y notas complementarias nacionales, asimismo el derecho arancelario $(\mathrm{A} / \mathrm{V})$ ha sido expresado en porcentaje, que se aplicará sobre el valor imponible. 
Por otro lado, se tiene como normas complementarias a las antes mencionadas al Texto Único Ordenado del Código Tributario aprobado por Decreto Supremo No 133-2013-EF publicado en el Diario Oficial El Peruano el 22 de junio de 2013 y el Texto Único Ordenado de la Ley del Impuesto General a las Ventas e Impuesto Selectivo al Consumo aprobado por Decreto Supremo N ${ }^{\circ}$ 055-99-EF publicado en el Diario Oficial El Peruano el 15 de abril de 1999 y vigente desde el 16 de abril de 1999.

También se tiene la Resolución Ministerial No 226-2005-MINCETUR/DM publicada en el Diario Oficial El Peruano el 27 de julio de 2005 que aplica Derechos Correctivos Provisionales Ad/Valorem y el Sistema de Franja de Precios aprobado por Decreto Supremo N ${ }^{\circ}$ 115-2001-EF y modificatorias.

\section{TRIBUTOS ADUANEROS}

De acuerdo a la consulta de la página Web de la Superintendencia Nacional de Aduanas y de Administración Tributaria - SUNAT, ${ }^{2}$ en ella se establece una síntesis de los tributos aduaneros que gravan la importación de mercancías:

3.1. Derechos ad/valorem: Derecho arancelario por excelencia que grava la importación de las mercancías. Siendo las tasas imponibles de $0 \%$, $4 \%$, $6 \%$ y $11 \%$, según la subpartida nacional, dicho porcentaje se aplica sobre la base imponible, determinada según el Acuerdo del Valor de la O.M.C.

3.2. Derechos correctivos provisionales ad valorem: Medidas correctivas aplicadas por el Perú a los demás países miembros de la Comunidad Andina que son de carácter no discriminatorio, de conformidad con el Acuerdo de Cartagena. Se aplica a las importaciones de mantecas bajo las subpartidas NANDINA 1511.90.00, 1516.20.00, y 1517.90.00, procedentes de Colombia, con una tasa de $29 \%$ ad/valorem CIF.

3.3. Derechos específicos-sistema de franja de precios: Tiene la naturaleza de derecho arancelario, grava las importaciones de los productos agropecuarios tales como arroz, maíz amarillo, leche y azúcar, fijando derechos variables adicionales y rebajas arancelarias según los niveles de precios piso y techo determinados en las tablas aduaneras. Los derechos variables adicionales y las rebajas arancelarias se determinarán en base a las tablas aduaneras y a los precios de referencia vigentes a la fecha de numeración de la declaración de importación, y se expresarán en dólares por tonelada. En ningún caso las rebajas arancelarias excederán la suma que corresponda pagar al importador por derecho ad/valorem correspondiente a cada producto.

2 http://www.sunat.gob.pe/orientacionaduanera/pagosgarantias/index.html. 
3.4. Impuesto selectivo al consumo - ISC: Es un impuesto indirecto que, a diferencia del IGV, solo grava determinados bienes (es un impuesto específico); una de sus finalidades es desincentivar el consumo de productos que generan externalidades negativas en el orden individual, social y medioambiental, como por ejemplo: las bebidas alcohólicas, cigarrillos y combustibles. El impuesto se aplica bajo el sistema al valor CIF aduanero, o bajo el sistema específico donde la base imponible lo constituye el volumen importado expresado en unidades de medida, o bajo el sistema al valor según precio de venta al público.

3.5. Impuesto general a las ventas - IGV (16\%): Este tributo grava la importación de todos los bienes, salvo las excepciones previstas en la normatividad que la regula. Su base imponible está determinada según el Acuerdo del Valor de la O.M.C. más los derechos arancelarios y demás impuestos que gravan la importación.

3.6. Impuesto de promoción municipal - IPM (2\%): Este tributo grava la importación de los bienes afectos al IGV, y su base imponible es la misma que corresponde al IGV.

3.7. Régimen de percepción del IGV - Venta interna: El régimen se aplica a las operaciones de importación definitiva que se encuentren gravadas con el IGV, y no será aplicable a las operaciones de importación exoneradas o inafectas a dicho impuesto. El importe de la operación está conformado por el valor CIF aduanero más todos los tributos que graven la importación y, de ser el caso, la salvaguardia provisional, los derechos correctivos provisionales, los derechos antidumping y compensatorios. Las modificaciones al valor en Aduanas o aquellas que se deriven de un cambio en las subpartidas nacionales declaradas en al DAM o DSI, serán tomadas en cuenta para la determinación del importe de la operación, aun cuando estas hayan sido materia de impugnación, siempre que se efectúe con anterioridad al levante de la mercancía y el importe de la percepción adicional que le corresponda al importador por tales modificaciones sea mayor a S/ 100,00. Se aplicará el $10 \%$ cuando el importador realice por primera vez una operación y/o régimen aduanero y estando inscrito en el RUC no se encuentre afecto al IGV, un $5 \%$ cuando el importador nacionalice bienes usados y un $3,5 \%$ en todos los demás casos que no correspondan a los dos primeros antes señalados.

También cabe precisar que la exportación de mercancía no está afecta al pago de ningún tributo. Por otro lado, determinadas mercancías están afectas al pago de derechos antidumping y compensatorios, siendo que los derechos antidumping se aplican a determinados bienes cuyos precios dumping causen o amenacen causar perjuicio a la producción peruana y los derechos compensatorios se aplican para contrarrestar cualquier subsidio concedido directa o indirectamente en el país de origen, cuando ello cause o amenace causar perjuicio a la producción peruana. Para la aplicación de ambos derechos debe existir una Resolución previa 
emitida por el Instituto Nacional de Defensa de la Competencia y de la Protección de la Propiedad Intelectual (INDECOPI). La base imponible lo constituye el monto al que asciende el valor FOB consignado en la factura comercial o en base al monto fijo por peso o por precio unitario. Monto: variable.

Asimismo, según lo dispuesto por la Sala de Aduana del Tribunal Fiscal de Perú, el Decreto Supremo No 133-91-EF establece las normas para evitar y corregir las distorsiones de la competencia en el mercado generadas por el dumping y los subsidios, señalando en el primer párrafo de su artículo $9^{\circ}$ que podrán establecerse derechos antidumping a la importación de todo producto a precio de dumping, cuando ella cause, o amenace causar, perjuicio a una producción en el Perú; además el tercer párrafo del referido artículo dispone que los derechos antidumping tienen la condición de detracciones compensatorias para evitar dańos a la economía del país y no constituyen, en forma alguna, tributo. En concordancia con lo precitado, el artículo 46 del Decreto Supremo No 006-2003-PCM que reglamenta las normas previstas en el Acuerdo Relativo a la Aplicación del Artículo VI del Acuerdo General sobre Aranceles Aduaneros y Comercio de 1994, el Acuerdo sobre Subvenciones y Medidas Compensatorias y en el Acuerdo sobre Agricultura, señala que los derechos antidumping son medidas destinadas a corregir las distorsiones generadas en el mercado por prácticas de dumping, como también que los derechos antidumping, provisionales o definitivos, tienen la condición de multa y no constituyen en forma alguna tributo.

Finalmente, cabe precisar que de conformidad con la Cuarta Disposición Complementaria del Decreto Supremo No 006-2003-PCM que aprobó el Reglamento sobre Medidas Antidumping y Compensatorias, los recursos impugnativos referidos estrictamente al cobro de derechos antidumping y/o compensatorios en los que se considere que exista una incorrecta aplicación por parte de Aduanas, deberán ser presentados ante el INDECOPI, previa acreditación del pago en caso de derechos definitivos o garantía en caso de derechos provisionales del monto impugnado y de la cancelación de la tasa respectiva.

\section{TLC PERÚ - MÉXICO}

\subsection{Antecedentes}

De acuerdo a la información consignada en la página Web del Ministerio de Comercio Exterior y Turismo de Perú, ${ }^{3}$ el Acuerdo de Integración Comercial Perú-México se firmó en Lima el 6 de abril de 2011 y entró en vigencia el 1 de febrero de 2012, de acuerdo a lo dispuesto en el Decreto Supremo No 001-2012-MINCETUR. Con anterioridad a la entrada en vigencia del Acuerdo de Integración Comercial, el intercambio comercial entre Perú y Méxi-

3 http://www.acuerdoscomerciales.gob.pe/index.php?option=com_content\&view=category\&layout=blog\&id=75\&Itemid $=98$ 
co se desarrollaba al amparo de lo dispuesto en el Acuerdo de Complementación Económica (ACE $\mathrm{N}^{\circ}$ 8), que fue suscrito en el año 1987 en el marco de la Asociación Latinoamericana de Integración (ALADI). Sin embargo, dicho Acuerdo contemplaba un ámbito muy limitado y un universo parcial de mercancías, ya que México otorgaba preferencias a 439 líneas arancelarias de las cuales solo 157 gozaban del $100 \%$ de preferencia, de otro lado Perú otorgaba 252 líneas arancelarias de las cuales solo 102 tenían $100 \%$ de preferencia. Asimismo, el ACE No 8 no contemplaba disposiciones en materia de servicios e inversiones.

Es así que las negociaciones para la ampliación y profundización del ACE $\mathrm{N}^{\circ} 8$ se iniciaron en enero de 2006 y fueron demoradas por coyunturas relacionadas con las políticas comerciales y de apertura de mercados para productos de la agroexportación. El Acuerdo negociado incorpora disciplinas en materia de acceso a mercados, reglas de origen, reconocimiento de denominaciones de origen, salvaguardias, prácticas desleales de comercio, obstáculos técnicos al comercio, normas sanitarias y fitosanitarias, reconocimiento mutuo de títulos profesionales, inversión, servicios, asuntos institucionales y solución de controversias.

Respecto al acceso a mercados tenemos que los principales beneficios para el Perú se reflejan en el acceso preferencial de más de 12000 productos. Así, productos de alto interés para el Perú, como los langostinos, flores, conservas de pescado, galletas dulces y vinos, ingresen al mercado mexicano libres de pago de arancel. Asimismo, algunas exportaciones peruanas del sector textil y confecciones podrán ingresar libres de pago de arancel a México a partir de la entrada en vigencia de este Acuerdo.

De otro lado, la importación desde México de bienes de consumo y productos de línea blanca y tecnología permitirá a los consumidores peruanos tener acceso a una mayor variedad y calidad de productos, a más bajo precio. Asimismo, se ha conseguido que México facilite la entrada a los peruanos que pretendan realizar actividades de negocios (investigación, ferias, convenciones comerciales), así como, actividades profesionales y técnicos de diversas ramas como diseño de interiores, construcción, arquitectura, gastronomía, entre otros.

Finalmente, en materia de inversiones se establece un conjunto de reglas relativas al tratamiento y protección de las inversiones entre México y Perú, lo cual permitirá fomentar un mayor flujo de inversiones mexicanas hacia el Perú, para permitir el aprovechamiento de las potencialidades productivas. Por otro lado, se generan las garantías para que las inversiones de empresas peruanas se puedan desarrollar en México. Cabe recordar que según la información brindada por el Ministerio de Comercio Exterior y Turismo de Perú, México es uno de nuestros principales socios comerciales en la región, cuenta con aproximadamente 112 millones de habitantes con un ingreso per cápita de US\$ 9250 y entre el 2000 y 2010 el intercambio comercial entre ambos países creció a una tasa promedio anual de $13,7 \%$, pasando de 389,2 millones de dólares en el 2000 a 1 412,8 millones de dólares en el 2010 . 


\subsection{Beneficios tributarios arancelarios}

El artículo 3.4 del Capítulo III del Acuerdo de Integración Comercial Perú-México dispone las siguientes pautas:

a. Salvo disposición distinta al Acuerdo, ninguna de las Partes podrá incrementar ningún arancel aduanero existente, ni adoptar ningún arancel aduanero nuevo, sobre mercancías originarias, sujetas al Programa de Eliminación Arancelaria.

b. Respecto a las mercancías excluidas del Programa de Eliminación Arancelaria, cualquier Parte podrá mantener o adoptar medidas de conformidad con sus derechos y obligaciones derivados del Acuerdo sobre la OMC y del Acuerdo de Integración Comercial Perú-México.

c. Salvo disposición distinta al Acuerdo, cada Parte eliminará sus aranceles aduaneros a mercancías originarias de conformidad con lo establecido en el Programa de Eliminación Arancelaria contenido en el Anexo del Artículo 3.4-A del Acuerdo.

d. Las Partes realizarán consultas, para examinar la posibilidad de mejorar las condiciones arancelarias de acceso a mercados para las mercancías originarias comprendidas en el Anexo del Artículo 3.4-A. del Acuerdo.

e. Salvo lo dispuesto en el Anexo del Artículo 3.4-B, las Partes podrán negar el trato arancelario preferencial conforme a este Acuerdo a mercancías usadas, reconstruidas, reparadas, recuperadas, remanufacturadas, o cualquier otra mercancía similar, o para restaurar la funcionalidad que tenían cuando eran nuevas.

f. Asimismo una Parte podrá incrementar un arancel aduanero a una mercancía originaria a un nivel no mayor al que establece su Lista en el Anexo del Artículo 3.4-A.

El artículo 3.9 del Capítulo III del Acuerdo de Integración Comercial Perú-México, dispone que salvo lo dispuesto en el Anexo del Artículo 3.9, ninguna Parte adoptará o mantendrá un impuesto, gravamen o cargo alguno sobre la exportación de mercancías destinadas al territorio de la otra Parte, a menos que estos se adopten o mantengan sobre dicha mercancía, cuando esté destinada al consumo interno.

El artículo 3.13 del Capítulo III del Acuerdo de Integración Comercial Perú-México dispone que cada Parte autorizará la importación libre de arancel aduanero a muestras comerciales de valor insignificante y a materiales de publicidad impresos importados del territorio de la otra Parte, independientemente de su origen.

La Sección 1 del Anexo del Artículo 3.4-A del Acuerdo de Integración Comercial PerúMéxico establece que para efectos de lo dispuesto en el Artículo 3.4, se aplicarán las siguientes categorías de desgravación indicadas en la columna 4 en la Lista de cada Parte: 
a) En la categoría de desgravación "A", se eliminarán para quedar libres de aranceles aduaneros a partir de la entrada en vigor del Acuerdo. Ejemplos:

\begin{tabular}{|c|c|c|c|c|c|}
\hline Columna 1 & Columna 2 & \begin{tabular}{|c|c|c|} 
Columna \\
3
\end{tabular} & \begin{tabular}{|c|c|} 
Columna \\
4
\end{tabular} & $\begin{array}{c}\text { Columna } \\
5\end{array}$ & $\begin{array}{c}\text { Columna } \\
6\end{array}$ \\
\hline Fracción & Descripción & Tasa Base & Categoria & Nota & SPFP \\
\hline 0507900000 & $\begin{array}{l}\text { Concha (caparazón) de tortuga, ballenas de mamiferos marinos (incluidas las barbas), } \\
\text { cuernos, astas, cascos, pezuñas, unas, garras y picos, en bruto o simplemente } \\
\text { preparados, pero sin cortar en forma determinada; polvo y desperdicios de estas mater }\end{array}$ & 12 & A & & \\
\hline 0508000000 & $\begin{array}{l}\text { Coral y materias similares, en bruto o simplemente preparados, pero sin otro trabajo; } \\
\text { valvas y caparazones de moluscos, crustáceos o equinodermos, y jibiones, en bruto o } \\
\text { simplemente preparados, pero sin cortar en forma determinada }\end{array}$ & 12 & A & & \\
\hline 0510001000 & $\begin{array}{l}\text { Bilis, incluso desecada; glándulas y demás sustancias de origen animal utilizadas para la } \\
\text { preparación de productos farmaceuticos, frescas, refrigeradas, congeladas o conservadas } \\
\text { provisionalmente de otra forma }\end{array}$ & 12 & A & & \\
\hline 0510009000 & Ámbar gris, castóreo, algalia y almizcle; cantáridas & 12 & $\mathbf{A}$ & & \\
\hline 0511100000 & Semen de bovino & $\begin{array}{l}\text { Libre de } \\
\text { arancel }\end{array}$ & A & & \\
\hline 0511911000 & Huevas y lechas de pescado & 12 & A & & \\
\hline 0511912000 & Desperdicios de pescado & 12 & A & & \\
\hline 0511919000 & $\begin{array}{l}\text { Demás productos de pescado o de crustáceos, moluscos o demás invertebrados } \\
\text { acuáticos: animales muertos de los capitulo } 1 \mathrm{\delta} 3 \text {, impropios para la alimentación humana }\end{array}$ & 12 & A & & \\
\hline 0511991000 & Cochinilla e insectos similares & 12 & A & & \\
\hline 0511993000 & Semen animal, excepto de bovino & $\begin{array}{l}\text { Libre de } \\
\text { arancel }\end{array}$ & A & & \\
\hline 0511994000 & Embriones & $\begin{array}{l}\text { Libre de } \\
\text { arancel }\end{array}$ & A & & \\
\hline 0511999020 & Esponjas naturales de origen animal & 4 & A & & \\
\hline 0511999090 & $\begin{array}{l}\text { Demás productos de origen animal no expresados ni comprendidos en otra parte; animales } \\
\text { muertos de los capítulos } 163 \text {, impropios para la alimentación humana }\end{array}$ & 12 & A & & \\
\hline 0601100000 & $\begin{array}{l}\text { Bulbos, cebollas, tubérculos, raices y bulbos tuberosos, turiones y rizomas, en reposo } \\
\text { vegetativo }\end{array}$ & 12 & A & & \\
\hline
\end{tabular}

b) En la categoría de desgravación "B3", se eliminarán en 3 cortes anuales iguales comenzando a partir de la entrada en vigor del Acuerdo, para quedar libres de aranceles aduaneros a partir del 1 de enero del año 3. Ejemplos:

\begin{tabular}{|l|l|l|l|}
\hline 12 & B3 & & \\
\hline
\end{tabular}

c) En la categoría de desgravación "B”, se eliminarán en 5 cortes anuales iguales comenzando a partir de la entrada en vigor del Acuerdo, para quedar libres de aranceles aduaneros a partir del 1 de enero del año 5. Ejemplos:

\begin{tabular}{|l|l|c|c|c|}
\hline 7418110000 & $\begin{array}{l}\text { Esponjas, estropajos, guantes y artículos similares para fregar, lustrar o usos análogos, de } \\
\text { cobre }\end{array}$ & 12 & B & \\
\hline 7418191000 & Aparatos no eléctricos de cocción o de calefacción y sus partes, de cobre & 12 & B & \\
\hline 7418199000 & Demás artículos de uso doméstico y sus partes, de cobre & 12 & B & \\
\hline 7418200000 & Artículos de higiene o de tocador y sus partes, de cobre & 12 & B & \\
\hline
\end{tabular}

d) En la categoría de desgravación "B7", se eliminarán en 7 cortes anuales iguales comenzando a partir de la entrada en vigor del Acuerdo, para quedar libres de aranceles aduaneros a partir del 1 de enero del año 7 . Ejemplos:

\begin{tabular}{|l|l|c|c|c|}
\hline 7321111200 & $\begin{array}{l}\text { Cocinas de uso doméstico, de combustible gaseoso, de gas y otros combustibles, de } \\
\text { fundición, hierro o acero, de mesa }\end{array}$ & 12 & $\mathrm{~B} 7$ & \\
\hline 7321111900 & $\begin{array}{l}\text { Demás cocinas de uso doméstico, de combustible gaseoso, de gas y otros combustibles, } \\
\text { de fundición, hierro o acero }\end{array}$ & 12 & $\mathrm{~B} 7$ & \\
\hline 7321119000 & $\begin{array}{l}\text { Aparatos de cocción y calientaplatos de uso doméstico, de combustible gaseoso, de gas y } \\
\text { otros combustibles, de fundición, hierro o acero, excepto las cocinas }\end{array}$ & 12 & $\mathrm{~B}$ & \\
\hline 7321120000 & $\begin{array}{l}\text { Aparatos de cocción y calientaplatos, de uso doméstico, de combustibles líquidos, de } \\
\text { fundición, hierro o acero }\end{array}$ & 12 & $\mathrm{~B} 7$ & \\
\hline 7321191000 & $\begin{array}{l}\text { Aparatos de cocción y calientaplatos, de uso doméstico, de combustibles sólidos, de } \\
\text { fundición, hierro o acero }\end{array}$ & 12 & $\mathrm{~B} 7$ & \\
\hline 7321199000 & $\begin{array}{l}\text { Demás aparatos de cocción y calientaplatos, de uso doméstico, de fundición, hierro o } \\
\text { acero, excepto de combustibles sólidos }\end{array}$ & 12 & $\mathrm{~B} 7$ & \\
\hline 7321810000 & $\begin{array}{l}\text { Aparatos de calefacción de uso doméstico, de combustibles gaseosos o de gas y otros } \\
\text { combustibles, de fundición, hierro o acero, excepto los de cocción }\end{array}$ & 12 & $\mathrm{~B} 7$ & \\
\hline
\end{tabular}


e) En la categoría de desgravación "C", se eliminarán en 10 cortes anuales iguales comenzando a partir de la entrada en vigor del Acuerdo, para quedar libres de aranceles aduaneros a partir del 1 de enero del año 10. Ejemplos:

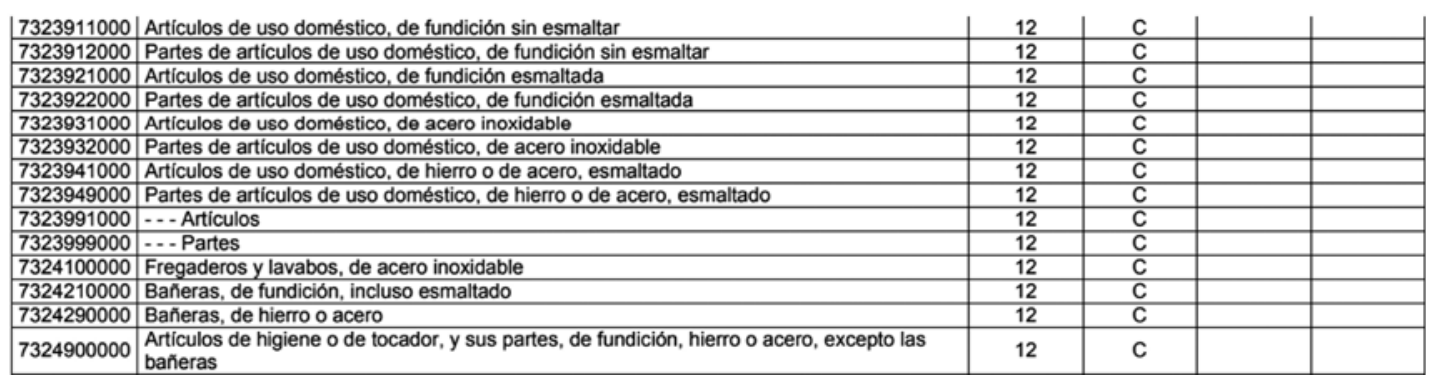

f) En la categoría de desgravación " $F$ ", estarán sujetas a las disposiciones establecidas en su respectiva nota indicada en la columna 5 en la Lista de cada Parte. Ejemplos:

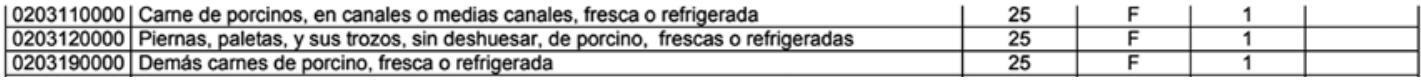

g) Las mercancías clasificadas en las fracciones arancelarias indicadas con "EXCL" se encuentran excluidas del Programa de Eliminación Arancelaria, de conformidad con lo establecido en el párrafo 2 del artículo 3.4 del Acuerdo. Ejemplos:

\begin{tabular}{|l|l|c|c|c|}
\hline 0201100000 & Carne de bovino, en canales o medias canales, fresca o refrigerada & $E X C L$ & \\
\hline 0201200000 & Demás cortes (trozos) sin deshuesar, de carne de bovino, frescas o refrigeradas & & $E X C L$ & \\
\hline 0201300010 & «cortes finos» de carne de bovino, deshuesada, fresca o refrigerada & & $E X L$ & \\
\hline 0201300090 & Demás carnes de bovino, deshuesada, fresca o refrigerada & $E X C L$ & \\
\hline 0202100000 & Carne de bovino, en canales o medias canales, congelada & $E X C L$ & \\
\hline 0202200000 & Demás cortes (trozos) sin deshuesar, de carne de bovino, congeladas & $E X C L$ & \\
\hline 0202300010 & «cortes finos» de carne de bovino, deshuesada, congelada & & \\
\hline 0202300090 & Demás carnes de bovino, deshuesada, congelada & & \\
\hline
\end{tabular}

h) Las mercancías clasificadas en las fracciones arancelarias indicadas con " $\mathrm{PROH}$ " en la Lista de México se encuentran prohibidas de conformidad III-14 con la Tarifa de la Ley de los Impuestos Generales de Importación y de Exportación. Ejemplos:

\begin{tabular}{|c|c|c|c|c|}
\hline 3003.40 .01 & Preparaciones a base de Cannabis indica. & $\mathrm{PROH}$ & PROH & \\
\hline 3003.40 .02 & Preparaciones a base de acetil morfina o de sus sales o derivados. & $\mathrm{PROH}$ & PROH & \\
\hline
\end{tabular}

Asimismo, la referida Sección 1 del Anexo del Artículo 3.4-A establece que cada Parte deberá asegurar que sus procedimientos para administrar los cupos sean transparentes, estén disponibles al público, sean oportunos, no discriminatorios, atiendan a las condiciones del mercado y no constituyan un obstáculo al comercio, adicionales a los derivados de la imposición del cupo; siendo que cualquier persona de una Parte que cumpla los requisitos legales y administrativos de esa Parte podrá ser elegible para la asignación de una cantidad dentro del cupo; y únicamente las autoridades gubernamentales administrarán sus cupos y no delegarán la administración de los mismos a grupos de productores u otras organizaciones no gubernamentales, salvo que se convenga algo distinto en el Acuerdo. 


\subsection{Actual flujo comercial de mercancías beneficiados entre México y Perú (estadísticas)}

Según el Plan de Desarrollo de Mercado de México elaborado por el Ministerio de Comercio Exterior y Turismo ${ }^{4}$, este identifica las oportunidades comerciales de productos y servicios en los sectores de alimentos y bebidas, forestal, construcción y diseńo de la moda, priorización de productos y servicios, tendencias del consumidor, canales de comercialización, distribución, regulaciones y el Plan de Acción, que permitirán un rápido aprovechamiento dentro de la dinámica comercial.

Asimismo, los Estados Unidos Mexicanos es la segunda economía más grande en Latinoamérica, después de Brasil, y en el 2013 fue el vigésimo primer destino de las exportaciones de Perú y la décima fuente de Inversión Extranjera Directa (IED) en el Perú, según lo señalado por PROINVERSIÓN. Sus principales ciudades son México D. F., Guadalajara, Monterrey y Puebla, siendo que la economía mexicana depende en gran medida de sus exportaciones de petróleo, así como del desempeño del intercambio comercial con su principal socio: Estados Unidos de América.

CUADRO Nº1

\begin{tabular}{|c|c|c|c|}
\hline Indicador & 2012 & 2013 & 2014 \\
\hline Población (Millones) & 117,06 & 118,40 & 119,58 \\
\hline PBI (USD Billones) & 1185,70 & 1260,92 & 1295,86 \\
\hline PBI per Cápita (USD) & 10129,42 & 10649,91 & 10836,69 \\
\hline $\begin{array}{l}\text { Inflación anual, precios consumidor fin } \\
\text { de periodo (Var \%) }\end{array}$ & 3,57 & 3,97 & 4,01 \\
\hline
\end{tabular}

Fuente: Fondo Monetario Internacional, World Economic Outlook Database, octubre 2014 * Cifras estimadas al 2014
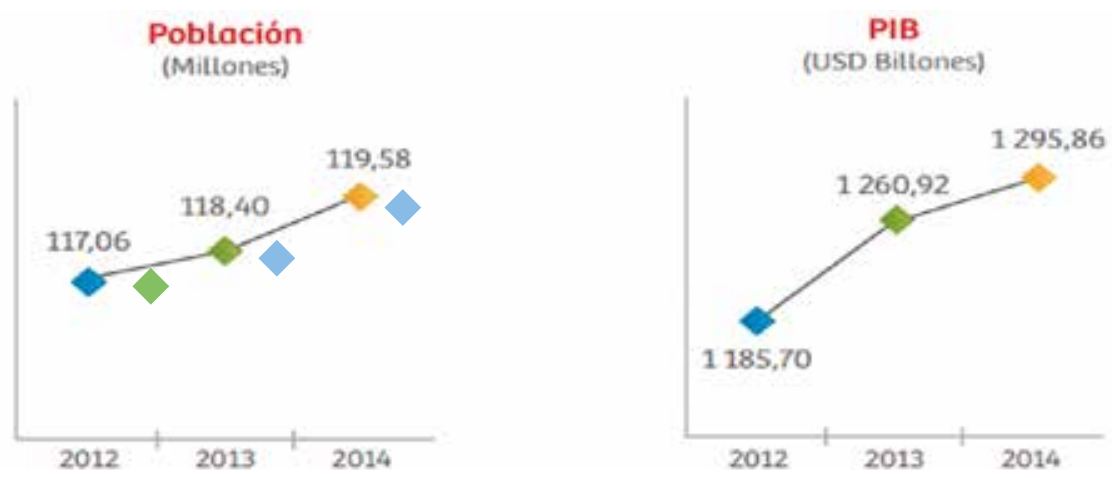

4 http://www.siicex.gob.pe/siicex/resources/sectoresproductivos/PDM\%20Mexico.pdf 
CUADRO $\mathrm{N}^{\circ} 02$

\begin{tabular}{|l|l|r|r|r|}
\hline \multicolumn{2}{|c|}{$\begin{array}{c}\text { Evaluación del Comercio } \\
\text { Perú - México (millones US\$) }\end{array}$} & 2012 & 2013 & \multicolumn{1}{|c|}{2014} \\
\hline (C) & Exportaciones (FOB) & 417 & 511 & 734 \\
\hline & (C) / (A) & $0,9 \%$ & $1,2 \%$ & $1,9 \%$ \\
\hline (D) & Importaciones (CIF) & 1675 & 1818 & 1925 \\
\hline & (D) / (B) & $4,0 \%$ & $4,2 \%$ & $4,6 \%$ \\
\hline & Saldo Comercial & -1258 & -1307 & -1190 \\
\hline
\end{tabular}

Fuente: SUNAT, BCM, FMI-IFS

Elaboración: MINCETUR

OGEE-OEEI

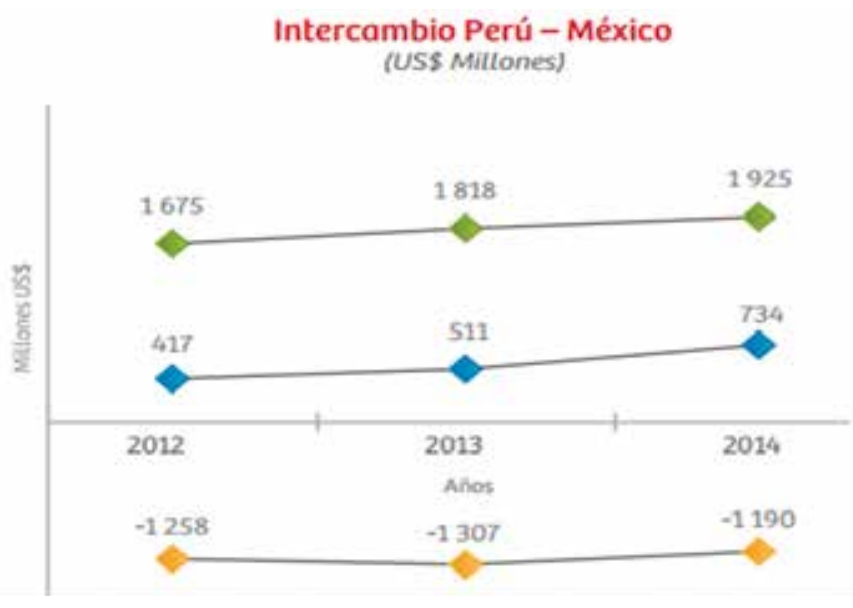

CUADRO $N^{\circ} 03$

Exportaciones por Sectores Económicos (US\$ Millones)

\begin{tabular}{|c|c|c|c|c|c|c|c|}
\hline Sector & 2015 & 2016 & Var. $\%$ & $\begin{array}{c}\text { Ene-Mar } \\
2016\end{array}$ & $\begin{array}{c}\text { Ene-Mar } \\
2017\end{array}$ & Var. $\%$ & Flujo \\
\hline & 547,0 & 466,1 & 7. $-14,8 \%$ & 101,2 & $78,3 \sqrt{7}$ & $-22,7 \pi$ & $-22,9$ \\
\hline Trodicional & 281.3 & 225.7 & $-20 \%$ & 37.8 & 17.01 & $-55 \%$ & -20.8 \\
\hline Petróleo y gas natural & 217,8 & 155,8 & \& $-28 \%$ & 28,5 & $5,4 \sqrt{7}$ & $-81 \%$ & $-23,1$ \\
\hline Minero & 51,3 & $\$ 1,9$ & $1 \%$ & 2,3 & 8.6 순 & $272 \%$ & 6,3 \\
\hline Pesquero & * & 0,0 & - & . & - & $\cdot$ & \\
\hline Agricola & 12,2 & 18,0 & $47 \%$ & 6,9 & $2,9 \sqrt{7}$ & $-58 \%$ & \\
\hline No Tradicional & 265,7 & 240.4 & $-10 x$ & 63.4 & 61.31 & $-3 \%$ & -2.2 \\
\hline Agropecuario & 50,6 & 70,5 & $39 \%$ & 24,0 & $19,6 \sqrt{7}$ & $-18 \%$ & $-4,4$ \\
\hline Textil & 29,4 & 26,5 & $-10 \%$ & 6,3 & 3,68 & $-43 \%$ & $-2,7$ \\
\hline Quimico & 53,9 & 62,9 & $17 \%$ & 13,7 & 14,2 슬 & $4 \%$ & 0,6 \\
\hline Pesquero & 10,9 & 10,1 & $-7 \%$ & 3,2 & 4,7 숨 & $45 \%$ & 1,5 \\
\hline Sidero-metalúrgico & 18,7 & 12,5 & $\sqrt{7} \cdot 33 \%$ & 2,8 & 3.0 술 & $8 \%$ & 0,2 \\
\hline Metal mecánico & 34,4 & 21,5 & \&. $-38 \%$ & 3,4 & 6,3 숨 & $86 \%$ & 2,9 \\
\hline Mineria no metalica & 25,1 & 9,1 & $\sqrt{7}-64 \%$ & 4,6 & $1,6 \downarrow$ & $-64 \%$ & $-2,9$ \\
\hline Otros* & 42,6 & 27,2 & i. $-36 \%$ & 5,4 & 8,1 순 & $\operatorname{sos}$ & 2,7 \\
\hline
\end{tabular}

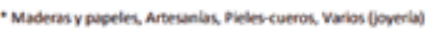

fuente: Sunut/tatoración: vace 


\section{CUADRO N 04 . EXPORTACIONES NO TRADICIONALES HACIA MÉXICO (US\$ Millones)}

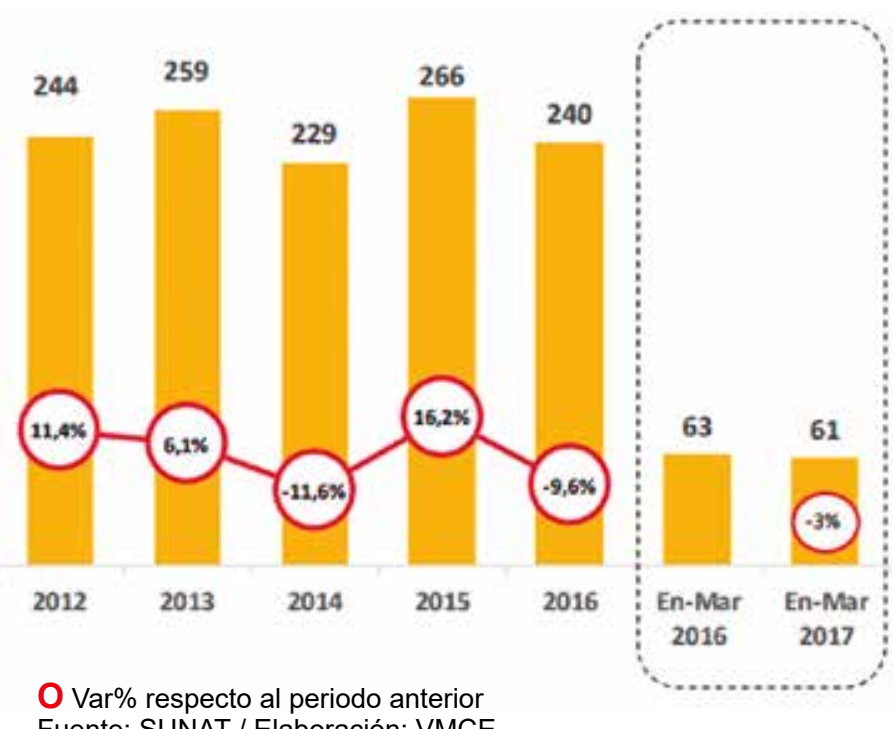

Fuente: SUNAT / Elaboración: VMCE

\section{CUADRO N ${ }^{\circ}$ 05. EXPORTACIONES NO TRADICIONALES POR SECTORES}

(Enero-Marzo, 2017, \%)

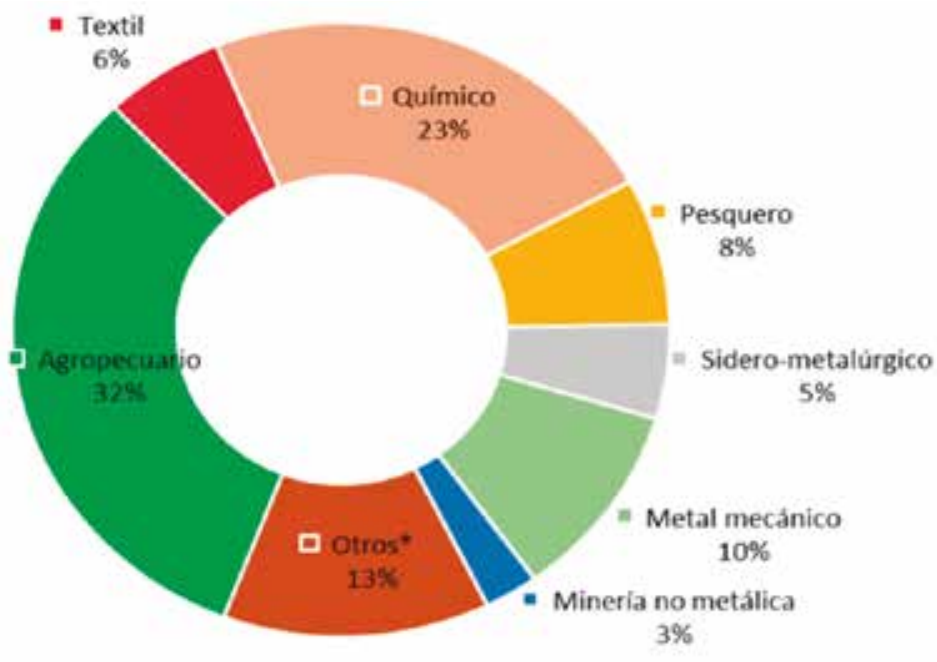

* Maderas y papeles, Artesanías, Pieles-cueros, Varios (joyería)

Fuente: SUNAT / Elaboración: VMCE 
CUADRO $N^{\circ} 06$

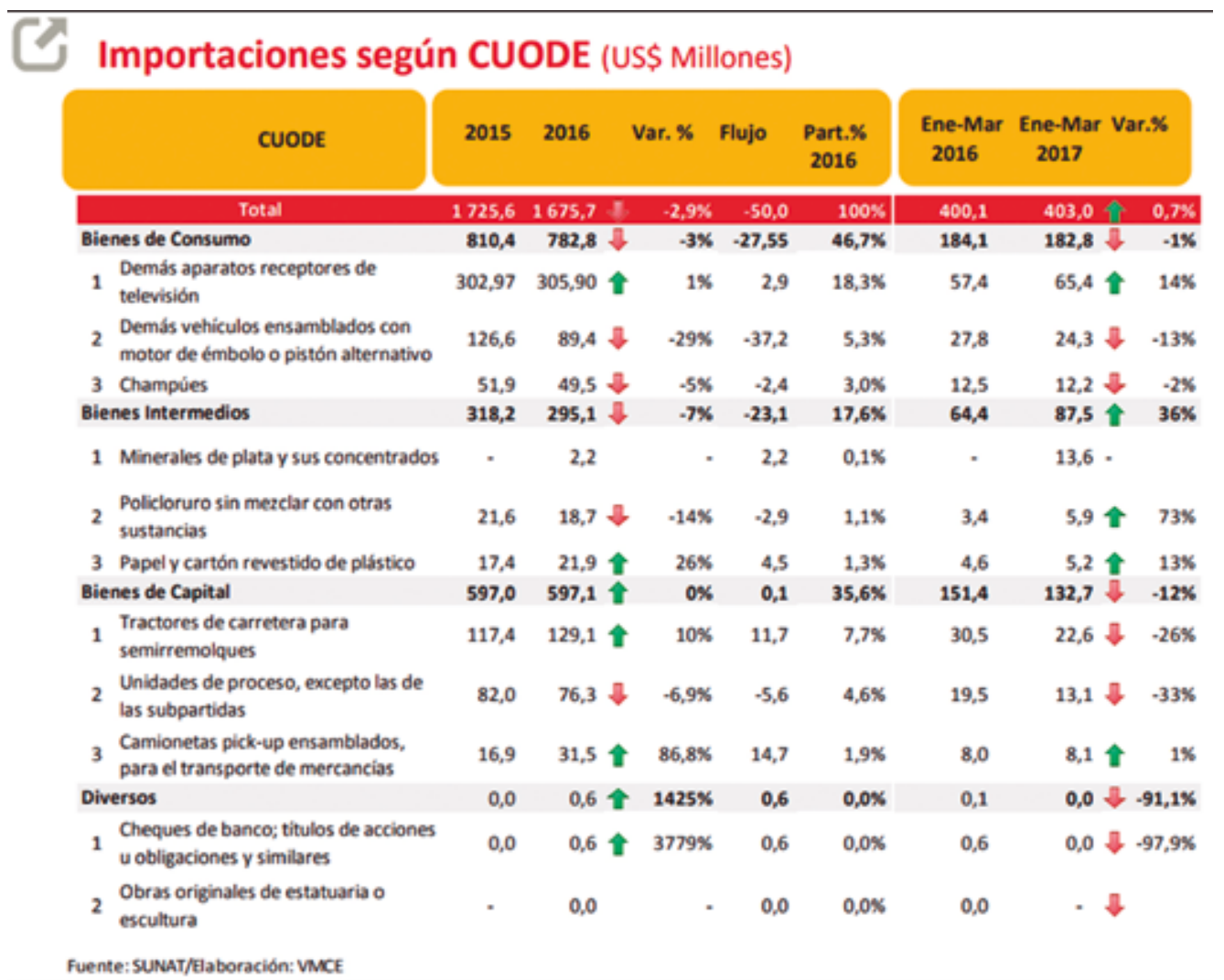

\section{ACUERDO DE ALIANZA DEL PACÍFICO PERÚ, MÉXICO, COLOMBIA Y CHILE}

\subsection{ANTECEDENTES}

De acuerdo a la información consignada en la página Web del Ministerio de Comercio Exterior y Turismo de Perú, ${ }^{5}$ la Alianza del Pacífico constituye un área de integración profunda para avanzar hacia la libre circulación de bienes, servicios, capitales y personas e impulsar un mayor crecimiento, desarrollo y competitividad de las economías de las Partes; por otro lado, entre diciembre de 2010 y marzo de 2011 se llevaron a cabo reuniones a nivel de presidentes (Mar del Plata, 4 de diciembre de 2010), de ministros de Comercio Exterior y Relaciones Exteriores (Santiago de Chile, 6 de enero de 2011) y de viceministros de Comercio Exterior

5 http://www.acuerdoscomerciales.gob.pe/index.php?option=com_content\&view=category\&layout=blog\&id=166\&Ite$\operatorname{mid}=185$ 
(Ciudad de México, 10 de marzo de 2011), con el fin de definir una hoja de ruta a seguir, la cual incorporaría no solo los temas tradicionales en materia comercial, sino otras áreas objeto de integración.

El 28 de abril de 2011, en la ciudad de Lima, los presidentes de Chile, Colombia, México y Perú suscribieron la Declaración de Lima, el primer documento formal que recoge la visión de la iniciativa. En dicha Declaración los países se comprometieron a avanzar progresivamente hacia el objetivo de alcanzar la libre circulación de bienes, servicios, capitales y personas, para lo cual se priorizarían trabajos en ciertas áreas que involucran movimiento de personas de negocios y facilitación para el tránsito migratorio; facilitación de comercio y cooperación aduanera; cooperación y mecanismos de solución de diferencias. Panamá participó en calidad de observador.

El 6 de junio de 2012, durante la IV Cumbre Presidencial, en Paranal (Chile), suscriben el Acuerdo Marco de la Alianza del Pacífico, Colombia, Chile, México y Perú como Estados miembros y Panamá y Costa Rica en calidad de estados observadores. En este mismo, se establecen como requisitos esenciales para que un Estado pueda participar, el reconocimiento a la vigencia del Estado de Derecho, la democracia, la separación de poderes del Estado y la protección y respeto a los derechos humanos y libertades fundamentales.

De esta manera, se han celebrado once cumbres presidenciales, la última de las cuales se realizó en Puerto Varas, Chile, en julio del 2016, donde se dio la firma del Segundo Protocolo Modificatorio al Protocolo Adicional al Acuerdo Marco.

\subsection{Beneficios tributarios arancelarios}

El artículo 3.4 del Capítulo 3 del Protocolo Adicional del Acuerdo Marco de la Alianza del Pacífico dispone las siguientes pautas:

a. Salvo disposición distinta en el Protocolo Adicional, cada Parte eliminará sus aranceles aduaneros sobre mercancías originarias de conformidad con su Lista de Eliminación Arancelaria establecida en el Anexo 3.4.

b. Salvo disposición distinta en el Protocolo Adicional, ninguna de las Partes podrá incrementar ningún arancel aduanero existente, ni adoptar ningún arancel aduanero nuevo sobre mercancías originarias.

c. Si en cualquier momento después de la fecha de entrada en vigor del Protocolo Adicional, una Parte reduce su arancel aduanero de nación más favorecida aplicado, dicho arancel se aplicará solo si es menor que el arancel resultante de la aplicación del Anexo 3.4 . 
d. A solicitud de cualquier Parte, esta y una o más Partes realizarán consultas, de conformidad con el Capítulo 3, para examinar la posibilidad de mejorar las condiciones arancelarias de acceso al mercado sobre mercancías originarias establecidas en sus respectivas listas de eliminación arancelaria del Anexo 3.4.

e. Un acuerdo entre dos o más Partes para mejorar las condiciones arancelarias de acceso al mercado sobre mercancías originarias prevalecerá sobre cualquier arancel aduanero o categoría de desgravación establecidas en sus respectivas listas de eliminación arancelaria en el Anexo 3.4.

f. Cuando una Parte decida acelerar unilateralmente la eliminación de aranceles aduaneros sobre las mercancías originarias de las otras Partes, deberá informar a las otras Partes antes de que el nuevo arancel aduanero entre en vigor.

g. Si una Parte mejora las condiciones arancelarias de acceso al mercado, los beneficios de esta mejora se extenderán a las demás Partes.

h. Una Parte podrá incrementar un arancel aduanero a ser aplicado a una mercancía originaria a un nivel no mayor al que establece el Anexo 3.4, o mantener o incrementar un arancel aduanero a una mercancía originaria, cuando sea autorizado por el Órgano de Solución de Diferencias de la OMC.

El artículo 3.10 del Capítulo 3 del Protocolo Adicional del Acuerdo Marco de la Alianza del Pacífico dispone que salvo lo dispuesto en el Anexo 3.10, ninguna Parte adoptará o mantendrá cualquier impuesto, gravamen o cargo alguno sobre las exportaciones de cualquier mercancía destinada al territorio de otra Parte, a menos que tal impuesto, gravamen o cargo sea también adoptado o mantenido sobre dicha mercancía cuando esté destinada al consumo interno.

Asimismo, el artículo 3.14 del Capítulo 3 del Protocolo Adicional del Acuerdo Marco de la Alianza del Pacífico dispone que cada Parte autorizará la importación libre de arancel aduanero a muestras comerciales de valor insignificante y a materiales de publicidad impresos importados del territorio de otra Parte, independientemente de su origen.

El Anexo 3.4 del Protocolo Adicional del Acuerdo Marco de la Alianza del Pacífico dispone que cada Parte aplicará, en los términos estipulados en su Lista de Eliminación Arancelaria, las siguientes categorías de desgravación a las mercancías originarias importadas desde el territorio de cada Parte, de conformidad con los Artículos 3.4 y 4.2 (criterios de origen), siendo que para los efectos del Anexo 3.4 y la Lista de Eliminación Arancelaria de cada Parte, después del año de entrada en vigor del Protocolo Adicional, cada reducción anual se realizará el 1 de enero del ańo siguiente, y para mayor certeza, en caso que el Protocolo Adicional entre en vigor después del año 2014, quedarán libres de aranceles aduaneros las mercancías cuya 
categoría prevea su eliminación total en uno o más ańos anteriores al de la fecha de entrada en vigor de dicho Protocolo Adicional.

En relación con las demás categorías, la eliminación arancelaria será de la siguiente forma:

- Categoría A: quedarán completamente eliminados a partir del año 2014. Ejemplos:

\begin{tabular}{|l|l|c|c|}
\hline $\begin{array}{c}\text { NANPERU } \\
\mathbf{2 0 1 2}\end{array}$ & \multicolumn{1}{|c|}{ Descripción } & $\begin{array}{c}\text { Tasa } \\
\text { Base }\end{array}$ & Categoría \\
\hline 0101210000 & - Reproductores de raza pura & 0 & A \\
\hline 0101291000 & - - Para carrera & 6 & A \\
\hline 0101299000 & - - Los demás & 6 & A \\
\hline 0101300000 & - Asnos & 0 & A \\
\hline 0101900000 & - Los demás & 0 & A \\
\hline 0102210000 & - - Reproductores de raza pura & 0 & A \\
\hline 0102291000 & - - Para lidia & 6 & A \\
\hline 0102299000 & - - Los demás & 0 & A \\
\hline
\end{tabular}

- Categoría B: se eliminarán en dos años, a partir del 2014, de acuerdo con los cortes establecidos en el cronograma del Anexo. Dichas mercancías quedarán libres de aranceles aduaneros a partir del 1 de enero del año 2015. Ejemplos:

\begin{tabular}{|l|l|c|c|}
\hline 1602100000 & - Preparaciones homogeneizadas & 25 & B \\
\hline
\end{tabular}

- Categoría C: se eliminarán en tres años, a partir del 2014, de acuerdo con los cortes establecidos en el cronograma del Anexo. Dichas mercancías quedarán libres de aranceles aduaneros a partir del 1 de enero del año 2016.

- Categoría D: se eliminarán en cuatro años, a partir del 2014, de acuerdo con los cortes establecidos en el cronograma del Anexo. Dichas mercancías quedarán libres de aranceles aduaneros a partir del 1 de enero del año 2017. Ejemplos:

\begin{tabular}{|l|l|c|c|}
\hline 1602200000 & - De hígado de cualquier animal & 25 & $\mathrm{D}$ \\
\hline
\end{tabular}

- Categoría E: se eliminarán en cinco años, a partir del 2014, de acuerdo con los cortes establecidos en el cronograma del Anexo. Dichas mercancías quedarán libres de aranceles aduaneros a partir del 1 de enero del año 2018. Ejemplos:

\begin{tabular}{|l|l|c|c|}
\hline 0206210000 & - - Lenguas & 12 & $\mathrm{E}$ \\
\hline 0206220000 & - - Higados & 12 & $\mathrm{E}$ \\
\hline 0206290000 & - - Los demás & 12 & $\mathrm{E}$ \\
\hline
\end{tabular}


- Categoría E5: se mantendrán desde 2014 y hasta 2018, de acuerdo con lo establecido en el cronograma del Anexo. Dichas mercancías quedarán libres de aranceles aduaneros el 1 de enero del año 2019.

- Categoría F: se eliminarán en seis años, a partir del 2014, de acuerdo con los cortes establecidos en el cronograma del Anexo. Dichas mercancías quedarán libres de aranceles aduaneros a partir del 1 de enero del ańo 2019.

- Categoría G: se eliminarán en siete años, a partir del 2014, de acuerdo con los cortes establecidos en el cronograma del Anexo. Dichas mercancías quedarán libres de aranceles aduaneros a partir del 1 de enero del año 2020. Ejemplos:

\begin{tabular}{|l|l|c|c|}
\hline 0201200000 & - Los demás cortes (trozos) sin deshuesar & 25 & G \\
\hline 0201300010 & - - Cortes finos & 25 & G \\
\hline 0201300090 & - - Los demás & 25 & G
\end{tabular}

- Categoría H: se eliminarán en ocho años, a partir del 2014, de acuerdo con los cortes establecidos en el cronograma del Anexo. Dichas mercancías quedarán libres de aranceles aduaneros a partir del 1 de enero del año 2021.

- Categoría I: se eliminarán en nueve años, a partir del 2014, de acuerdo con los cortes establecidos en el cronograma del presente Anexo. Dichas mercancías quedarán libres de aranceles aduaneros a partir del 1 de enero del año 2022.

- Categoría J: se eliminarán en diez años, a partir del 2014, de acuerdo con los cortes establecidos en el cronograma del Anexo. Dichas mercancías quedarán libres de aranceles aduaneros a partir del 1 de enero del año 2023. Ejemplos:

\begin{tabular}{|c|l|c|c|}
\hline 0403100020 & $\begin{array}{l}\text { - - Aromatizados o con frutas u otros frutos o cacao, incluso con adición de } \\
\text { azúcar y otro edulcorante }\end{array}$ & 25 & $\mathrm{~J}$ \\
\hline 0403100090 & - - Los demás & 25 & $\mathrm{~J}$ \\
\hline 0403901000 & - - Suero de mantequilla & 25 & $\mathrm{~J}$ \\
\hline 0403909010 & $\begin{array}{l}\text { - - Aromatizados o con frutas u otros frutos o cacao, incluso con adición de } \\
\text { azúcar y otro edulcorante }\end{array}$ & 25 & $\mathrm{~J}$ \\
\hline 0403909090 & - - Los demás & 25 & $\mathrm{~J}$ \\
\hline
\end{tabular}

- Categoría J5: se mantendrán de 2014 y hasta 2018, de acuerdo con lo establecido en el cronograma del Anexo. Dichas mercancías se desgravarán linealmente a partir del 1 de enero del ańo 2019, quedando libres de aranceles aduaneros a partir del 1 de enero del año 2023.

- Categoría K: se eliminarán en doce años, a partir del 2014, de acuerdo con los cortes establecidos en el cronograma del Anexo. Dichas mercancías quedarán libres de aranceles aduaneros a partir del 1 de enero del año 2025. Ejemplos: 


\begin{tabular}{|l|l|c|c|}
\hline 1006200000 & - Arroz descascarillado (arroz cargo o arroz pardo) & 52 & $\mathrm{~K}$ \\
\hline 1006300000 & - Arroz semiblanqueado o blanqueado, incluso pulido o glaseado & 52 & $\mathrm{~K}$ \\
\hline 1006400000 & - Arroz partido & 52 & $\mathrm{~K}$ \\
\hline
\end{tabular}

- Categoría K3: se mantendrán de 2014 y hasta 2016, de acuerdo con lo establecido en el cronograma del Anexo. Dichas mercancías se desgravarán linealmente a partir del 1 de enero del año 2017, quedando libres de aranceles aduaneros a partir del 1 de enero del año 2025. Ejemplos:

\begin{tabular}{|l|l|l|l|}
\hline 0207130011 & - - - S Sin deshuesar & 25 & K3 \\
\hline
\end{tabular}

- Categoría K5: se mantendrán de 2014 y hasta 2018, de acuerdo con lo establecido en el cronograma del Anexo. Dichas mercancías se desgravarán linealmente a partir del 1 de enero del año 2019, quedando libres de aranceles aduaneros a partir del 1 de enero del año 2025. Ejemplos:

\begin{tabular}{|l|l|c|c|}
\hline 0406100000 & -Queso fresco (sin madurar), incluido el del lactosuero, y requesón & 25 & K5 \\
\hline 0406200000 & - Queso de cualquier tipo, rallado o en polvo & 25 & K5 \\
\hline 0406300000 & - Queso fundido, excepto el rallado o en polvo & 25 & K5 \\
\hline 0406400000 & $\begin{array}{l}\text { - Queso de pasta azul y demás quesos que presenten vetas producidas por } \\
\text { Penicillium roqueforti }\end{array}$ & 25 & K5 \\
\hline
\end{tabular}

- Categoría K7: se mantendrán de 2014 y hasta 2020, de acuerdo con lo establecido en el cronograma del Anexo. Dichas mercancías se desgravarán linealmente a partir del 1 de enero del año 2021, quedando libres de aranceles aduaneros a partir del 1 de enero del año 2025. Ejemplos:

\begin{tabular}{|l|l|l|l|l|}
\hline 0904221000 & -. - Paprika (Capsicum annuum, L.) & 0 & K7 & $\begin{array}{l}\text { Tratamiento } \\
\text { aplicable } \\
\text { únicamente a } \\
\text { México }\end{array}$ \\
\hline
\end{tabular}

- Categoría L: se eliminarán en trece años, a partir del 2014, de acuerdo con los cortes establecidos en el cronograma del Anexo. Dichas mercancías quedarán libres de aranceles aduaneros a partir del 1 de enero del año 2026.

- Categoría M: se eliminarán en quince años, a partir del 2014, de acuerdo con los cortes establecidos en el cronograma del Anexo. Dichas mercancías quedarán libres de aranceles aduaneros a partir del 1 de enero del ańo 2028. Ejemplos:

\begin{tabular}{|l|l|c|c|l|}
\hline $0711900000 \mathrm{~B}$ & - Las demás hortalizas; mezclas de hortalizas, sólo cebollas & 11 & $\mathrm{M}$ & $\begin{array}{l}\text { Tratamiento } \\
\text { aplicable } \\
\text { únicamente a } \\
\text { Mexico }\end{array}$ \\
\hline
\end{tabular}


- Categoría N: se eliminarán en dieciséis años, a partir del 2014, de acuerdo con los cortes establecidos en el cronograma del Anexo. Dichas mercancías quedarán libres de aranceles aduaneros a partir del 1 de enero del año 2029.

- Categoría N3: se mantendrán de 2014 y hasta 2016, de acuerdo con lo establecido en el cronograma del Anexo. Dichas mercancías se desgravarán linealmente a partir del 1 de enero del ańo 2017, quedando libres de aranceles aduaneros a partir del 1 de enero del año 2029.

- Categoría N8: se mantendrán de 2014 y hasta 2021, de acuerdo con lo establecido en el cronograma del Anexo. Dichas mercancías se desgravarán linealmente a partir del 1 de enero del año 2022, quedando libres de aranceles aduaneros a partir del 1 de enero del año 2029.

- Categoría O: se eliminarán en diecisiete años, a partir del 2014, de acuerdo con los cortes establecidos en el cronograma del Anexo. Dichas mercancías quedarán libres de aranceles aduaneros a partir del 1 de enero del año 2030. Ejemplos:

\begin{tabular}{|l|l|c|c|l|}
\hline 0710100000 & - Papas (patatas) & 6 & o & $\begin{array}{l}\text { Tratamiento } \\
\text { aplicable } \\
\text { únicamente a } \\
\text { México }\end{array}$ \\
\hline
\end{tabular}

- Categoría O4: se mantendrán de 2014 y hasta 2017, de acuerdo con lo establecido en el cronograma del Anexo. Dichas mercancías se desgravarán linealmente a partir del 1 de enero del ańo 2018, quedando libres de aranceles aduaneros a partir del 1 de enero del año 2030.

- Categoría O12: se mantendrán de 2014 y hasta 2025, de acuerdo con lo establecido en el cronograma del Anexo. Dichas mercancías se desgravarán linealmente a partir del 1 de enero del año 2026, quedando libres de aranceles aduaneros a partir del 1 de enero del año 2030.

- Categoría P: se eliminarán de acuerdo a la estacionalidad definida en la columna observación y en los plazos ahí expresados en el cronograma del Anexo. Ejemplos:

\begin{tabular}{|l|l|l|l|l|}
\hline 0703100000 & - Cebollas y chalotes & & & $\begin{array}{l}\text { Tratamiento } \\
\text { aplicable } \\
\text { unnicamente a } \\
\text { México. } \\
\text { Desgravación } \\
\text { Inmediata: Enero } \\
\text { - Junio. 15 años: } \\
\text { Julio- Diciembre }\end{array}$ \\
\hline
\end{tabular}

- Categoría X: las mercancías clasificadas en esta categoría no estarán sujetas a la desgravación arancelaria. Las tasas arancelarias en cada etapa serán redondeadas hacia abajo, al menos al décimo punto porcentual más cercano o, si la tasa arancelaria está expre- 
sada en unidades monetarias, al menos al 0,001 más cercano de la unidad monetaria oficial de la Parte. Ejemplos

\begin{tabular}{|l|l|l|l|l|}
\hline 1701130000 & - - Azúcar de caña mencionado en la Nota 2 de subpartida de este Capítulo & & X & $\begin{array}{l}\text { Para este } \\
\text { producto, Perú } \\
\text { aplicará su } \\
\text { arancel ad- } \\
\text { valorem vigente } \\
\text { al momento de la } \\
\text { importación. }\end{array}$ \\
\hline
\end{tabular}

5.3. Actual flujo comercial de mercancías beneficiado entre México y Perú (estadísticas)

\section{CUADRO N 07}

\begin{tabular}{|lc|c|c|c|}
\hline \multicolumn{1}{|c|}{ Paises Miembros } & $\begin{array}{c}\text { PBI corriente o nominal } \\
-2016 \\
\text { (Mil millones US\$) }\end{array}$ & $\begin{array}{c}\text { PBI Per cápita PPP } \\
\text { (2016) }\end{array}$ & $\begin{array}{c}\text { Población 2016 } \\
\text { (Millones) }\end{array}$ \\
\hline Chile & $\star$ & 247 & 23,960 & 17,91 \\
\hline Colombia & & 282 & 14,158 & 48,65 \\
\hline México & 1046 & 17,862 & 127,54 \\
\hline Perú & & 192 & 13,022 & 31,77 \\
\hline
\end{tabular}

Fuente: Estimado BM (2016)

\section{CUADRO N 08}

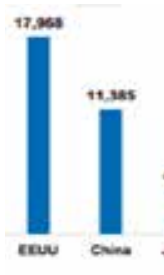

\section{Octava economía mundial}

PBI 2015

(Miles de Millones de US\$)

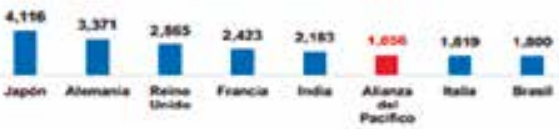

\section{Quinto mercado más grande} según población

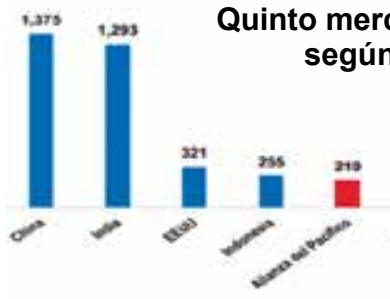

Población 2015 (Millones de habitantes)

in ${ }^{200}$ in

Fuente: *Estimado WEO-FMI

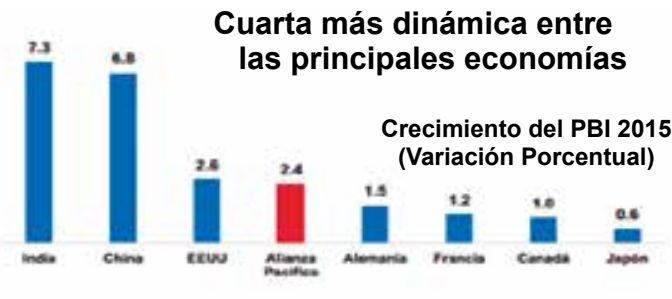

Séptima economía exportadora

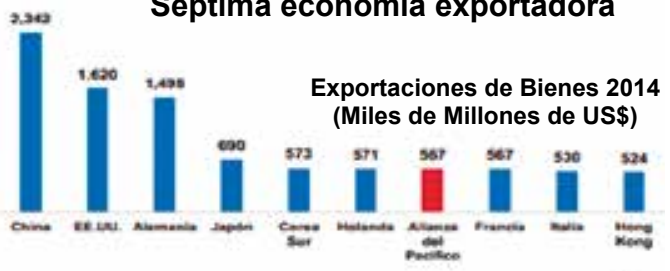




\section{CUADRO Nº9. MÉXICO REPRESENTÓ EL 22\% DE NUESTRAS EXPORTACIONES A LA ALIANZA DEL PACÍFICO EN EL 2016}

En el período de enero a julio del 2017 , las exportaciones peruanas no tradicionales han crecido en $74 \%$ con respecto al mismo período del año anterior

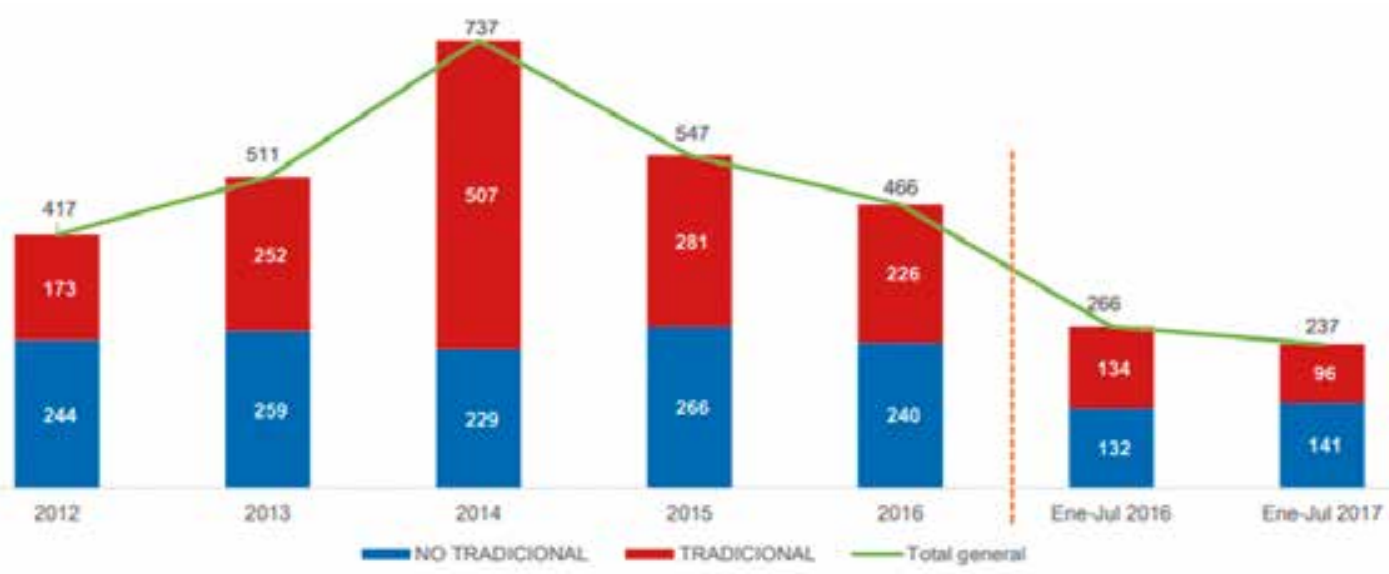

Fuente: SUNAT. Elaboración: PROMPERÚ

CUADRO No 10. PRINCIPALES PRODUCTOS EXPORTADOS NO TRADICIONALES. EXPORTADOS POR PERÚ EN 2016

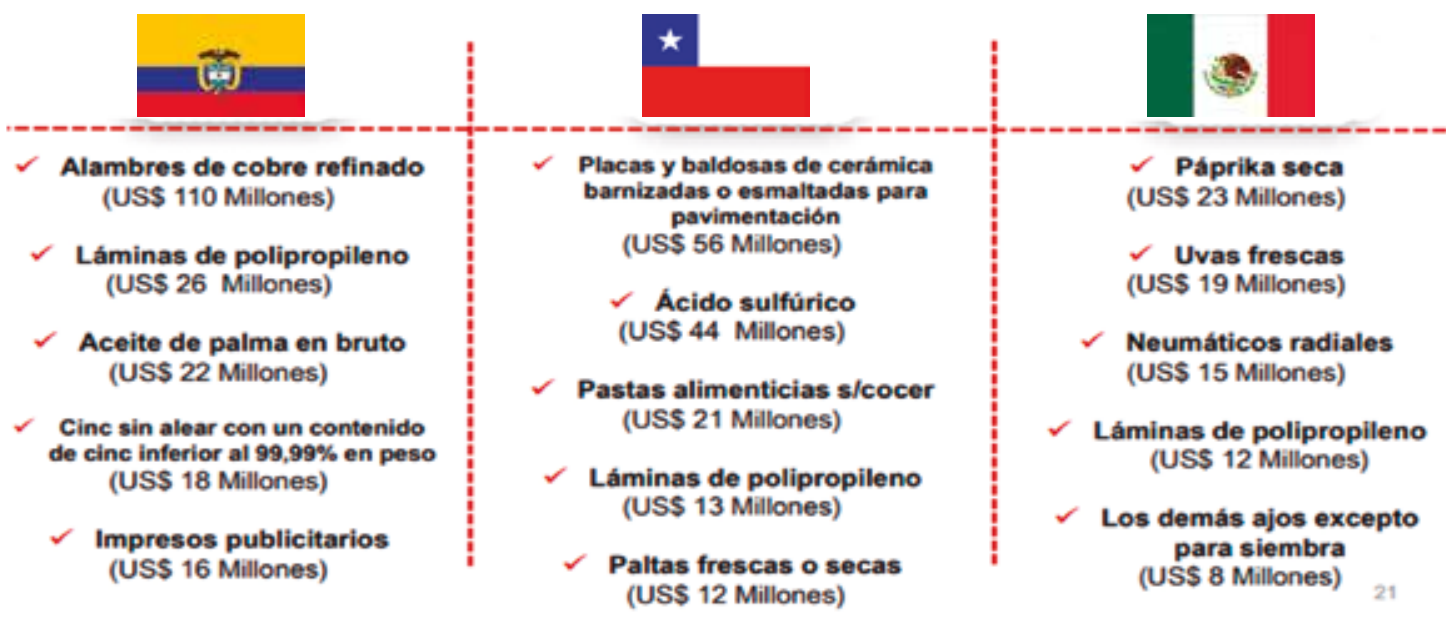

Fuente: SUNAT. Elaborado: PROMPERÚ 


\section{CASUÍSTICA SOBRE EL ACOGIMIENTO AL TRATADO DE LIBRE CO- MERCIO (TLC) ENTRE PERÚ Y MÉXICO}

De acuerdo a lo dispuesto en las resoluciones del Tribunal Fiscal No 14304-A-2013 emitida el 12 de setiembre de 2013, 11904-A-2015 emitida el 09 de diciembre de 2015, 12300A-2015 emitida el17 de diciembre de 2015, entre otras, por la Sala de Aduanas del Tribunal Fiscal $^{6}$ se dispuso el siguiente criterio interpretativo en materia de acogimiento al Tratado de Libre Comercio - TLC entre Perú y México:

a) La pretensión del importador se centra en incluir en las casillas 7.9, 7.23 y 7.37 del ejemplar A1 de la Declaración Aduanera de Mercancías, el certificado de origen, el TPI 809 e información complementaria referida al registro de la firma del funcionario autorizado respectivamente, con la finalidad de acogerse a los beneficios arancelarios del Acuerdo de Integración Comercial entre la República del Perú y los Estados Unidos Mexicanos.

b) Sin embargo, considerando el marco normativo precitado, el acogimiento al trato arancelario preferencial del referido tratado, de manera excepcional, se puede efectuar mediante solicitud de devolución de los tributos pagados en exceso respecto de una Declaración Aduanera de Mercancías.

c) En tal sentido, la solicitud de rectificación de la declaración aduanera no es la vía idónea para evaluar el acogimiento a la referida preferencia arancelaria, sin perjuicio que al amparo del artículo $213^{\circ}$ de la Ley del Procedimiento Administrativo General, Ley No 27444, se le dé el trámite de solicitud de devolución a la solicitud de rectificación en cuanto pretende acogerse al tratado en cuestión.

d) En consecuencia, no procede la rectificación de las series de la Declaración Aduanera de Mercancías en los términos solicitados por el importador, debiendo la Administración Aduanera remitir los actuados al área correspondiente para que se pronuncien sobre la solicitud de devolución planteada a efectos de evaluar el acogimiento al Acuerdo de Integración Comercial entre la República del Perú y los Estados Unidos Mexicanos, en el que evaluará los demás argumentos vertidos por el importador orientados a que se le apliquen los beneficios arancelarios previstos en tal acuerdo.

Asimismo, según lo dispuesto en las Resoluciones del Tribunal Fiscal No 13364-A-2014 emitida el 06 de noviembre de 2014, 15586-A-2014 emitida el 26 de diciembre de 2014, 00066-A-2015 emitida el 07 de enero de 2015, entre otras, por la Sala de Aduanas del Tribunal Fiscal se dispuso el siguiente criterio interpretativo:

6 El Tribunal Fiscal es un órgano resolutivo del Ministerio de Economía y Finanzas que depende administrativamente del Ministro, con autonomía en el ejercicio de sus funciones específicas. 
a) Las mercancías originarias de México fueron transportadas con destino al Perú, a través de un país no participante del Acuerdo (Los Ángeles - Estados Unidos de América), supuesto previsto en el inciso b) del numeral 1 del Artículo 4.17 del Acuerdo; en consecuencia, para que las mercancías se beneficien del trato arancelario preferencial debe cumplirse que:

- Las mercancías deben haber sido expedidas directamente del país exportador al país importador.

- El transporte en tránsito de las mercancías por el territorio de terceros países, con o sin transbordo o almacenamiento temporal, haya sido bajo la vigilancia de la autoridad aduanera competente.

- Las mercancías no hayan sido destinadas al comercio, uso o empleo, durante su transporte por el territorio de terceros países.

- Durante su transporte y almacenamiento por el territorio de terceros países, las mercancías no han debido sufrir ninguna operación distinta a la carga y descarga o cualquier operación, con el objeto de mantenerlas en buenas condiciones o asegurar su conservación.

b) Los presupuestos legales señalados en el considerando precedente son concurrentes, es decir, basta que uno de ellos no ocurra, para que el requisito de expedición directa no se cumpla, siendo además que los mismos se acreditan, en el caso de tránsito, con el documento de transporte, el que sustentará el transporte desde el país de origen al país de importación.

c) En el caso bajo estudio, se advierte que la empresa importadora presentó como únicos medios de prueba para acreditar el cumplimiento del requisito de expedición directa, el Conocimiento de Embarque, Transportation Entry and Manifest of Goods Subject to CBP Inspection and Permit, Straight Bill of Lading, Factura de Exportación y el Pedimento.

d) $\mathrm{Al}$ respecto se debe indicar que efectivamente el Conocimiento de Embarque, emitido por la empresa de transporte Maersk Line, sustenta únicamente el transporte de las mercancías materia de controversia, realizados por vía marítima desde el Puerto de Los Ángeles - Estados Unidos de América (Puerto de Embarque), con transbordo en Balboa y con puerto de descarga en Callao - Perú.

e) Ahora bien, con relación a los documentos presentados a fin de acreditar el transporte desde Tijuana - México a Los Ángeles - Estados Unidos de América, cabe señalar que estos no constituyen el documento de transporte; sin embargo, de la evaluación realizada a Transportation Entry and Manifest of Goods Subject to CBP Inspection and Permit (documento aduanero) se verifica que las mercancías importadas materia 
de evaluación fueron ingresadas mediante transporte terrestre por la empresa GOLD POINT TRANSPORTATION INC, provenientes desde México, para su transporte a Los Ángeles con destino final Callao - Perú, señalándose la información de un número en la casilla en la que se consigna el número del documento de transporte $(\mathrm{B} / \mathrm{L}$ No), mismo número que se señala en los Cargo Release / Manifest Results, o Manifiesto que consta en los actuados.

f) Asimismo, dicha información se consigna en el manifiesto de los actuados (Cargo Release / Manifest Results), en los que se señala que las mercancías se transportaron por vía terrestre, mediante camiones, señalándose como número de Master Bill GPON340953141.

g) Si bien no consta en los actuados el documento de transporte consignado en Transportation Entry and Manifest of Goods Subject to CBP Inspection and Permit, la Administración Aduanera debió verificar si efectivamente la información señalada como GPON340953141 corresponde a los documentos de transporte o si existió documento de transporte que sustente el traslado realizado desde México a Estados Unidos de América, ya sea documento físico o electrónico, solicitando la información a la Aduana de Estados Unidos de América en aplicación del Acuerdo de Promoción Comercial Perú - Estados Unidos (en relación a la cooperación y asistencia mutua que se deben al respecto).

\section{CONCLUSIONES}

1) El Sistema Tributario Aduanero se encuentra amparado en la Ley General de Aduanas aprobada por Decreto Legislativo No 1053 y su Reglamento aprobado por Decreto Supremo No 010.2009-EF. Además, se tiene al arancel de Aduanas aprobado por Decreto Supremo No 342-2016-EF; por otro lado, se tiene como normas complementarias a las antes mencionadas al Texto Único Ordenado del Código Tributario aprobado por Decreto Supremo No 133-2013-EF, el Texto Único Ordenado de la Ley del Impuesto General a las Ventas e Impuesto Selectivo al Consumo aprobado por Decreto Supremo No 055-99-EF, la Resolución Ministerial No 226-2005-MINCETUR/DM que aplica derechos correctivos provisionales ad/valorem y el sistema franja de precios aprobado por Decreto Supremo No 115-2001-EF y modificatorias.

2) Los tributos aduaneros aplicables a la importación son los derechos ad/valorem contenidos en el arancel de Aduanas, los derechos correctivos provisionales ad valorem, los derechos específicos-sistema de franja de precios, el impuesto selectivo al consumo -ISC, el impuesto general a las ventas -IGV, el impuesto de promoción municipal -IPM y el régimen de percepción del IGV - venta interna. También cabe precisar que la exportación de mercancía no está afecta al pago de ningún tributo. Asimismo, los 
derechos antidumping son medidas destinadas a corregir las distorsiones generadas en el mercado por prácticas de dumping, como también que los derechos antidumping, provisionales o definitivos, tienen la condición de multa y no constituyen tributo.

3) El Tratado de Libre Comercio suscrito entre el Perú y México genera las garantías para que las inversiones de empresas peruanas se puedan desarrollar en México. Cabe recordar que según la información brindada por el Ministerio de Comercio Exterior y Turismo de Perú, México es uno de nuestros principales socios comerciales en la región, cuenta con aproximadamente 112 millones de habitantes con un ingreso per cápita de US\$ 9250 y entre el 2000 y 2010 el intercambio comercial entre ambos países creció a una tasa promedio anual de $13,7 \%$, pasando de 389,2 millones de dólares en el 2000 a 1 412,8 millones de dólares en el 2010.

4) La Alianza del Pacífico constituye un área de integración profunda para avanzar hacia la libre circulación de bienes, servicios, capitales y personas e impulsar un mayor crecimiento, desarrollo y competitividad de las economías de las Partes; cabe precisar que dicha Alianza nació como iniciativa del Perú, para conformar un "área de integración profunda”, en la que se asegure plena libertad para la circulación de bienes, servicios, capitales y personas, con miras a convertir este espacio en un modelo de integración para la región, consolidando además una plataforma económica común con proyección a otras partes del mundo, especialmente el Asia.

5) El acogimiento al trato arancelario preferencial del Tratado de Libre Comercio suscrito entre el Perú y México, de manera excepcional, se puede efectuar mediante solicitud de devolución de los tributos pagados en exceso respecto de una Declaración Aduanera de Mercancías.

6) Para que las mercancías se beneficien del trato arancelario preferencial del Tratado de Libre Comercio suscrito entre el Perú y México, las mercancías deben haber sido expedidas directamente del país exportador al país importador, el transporte en tránsito de las mercancías por el territorio de terceros países, con o sin transbordo o almacenamiento temporal, haya sido bajo la vigilancia de la autoridad aduanera competente, las mercancías no hayan sido destinadas al comercio, uso o empleo, durante su transporte por el territorio de terceros países y durante su transporte y almacenamiento por el territorio de terceros países, las mercancías no han debido sufrir ninguna operación distinta a la carga y descarga o cualquier operación, con el objeto de mantenerlas en buenas condiciones o asegurar su conservación. 


\section{BIBLIOGRAFÍA CONSULTADA}

- Cantuarias Salaverry, Fernando y Pierino Stucchi López Raygada. TLC Perú-Estados Unidos: contenido y aplicación. Lima: Editorial Universidad Peruana de Ciencias Aplicadas, 2008.

- Basaldúa, R. Introducción al derecho aduanero. Buenos Aires: Editorial Abeledo Perrot, 1988.

- Congreso de la República, Luciana León Romero. Acuerdos Comerciales del Perú. Lima: Imprenta del Congreso de la República, 2013.

- Ministerio de Comercio Exterior y Turismo. "Reporte Mensual de Comercio" (enero, 2017). https://www.mincetur.gob.pe/wp-content/uploads/documentos/comercio_exterior/estadisticas_y_publicaciones/estadisticas/exportaciones/2017/RMC_Enero_2017. pdf

- Ministerio de Comercio Exterior y Turismo. "Reporte Mensual de Comercio" (marzo, 2017). https://www.mincetur.gob.pe/wp-content/uploads/documentos/comercio_exterior/estadisticas_y_publicaciones/estadisticas/exportaciones/2017/RMC_Enero_Marzo_2017.pdf

- Ley General de Aduanas, aprobada por Decreto Legislativo № 1053.

- Reglamento de la Ley General de Aduanas, aprobado por Decreto Supremo Nº10-2009EF.

- Procedimiento Específico: Aplicación de Preferencias al amparo del AIC PERÚ - MÉXICO - DESPA-PE.01.28.

- Procedimiento Específico: Aplicación de Preferencias al amparo del Protocolo Adicional al Acuerdo marco de la Alianza del Pacífico - DESPA.PE.01.34.

- Acuerdo de Integración Comercial Perú - México, de acuerdo a lo dispuesto en el Decreto Supremo No 001-2012-MINCETUR.

- Protocolo Adicional al Acuerdo Marco de la Alianza del Pacífico.

RECIBIDO: 27/09/2018

APROBADO: 08/11/2018 


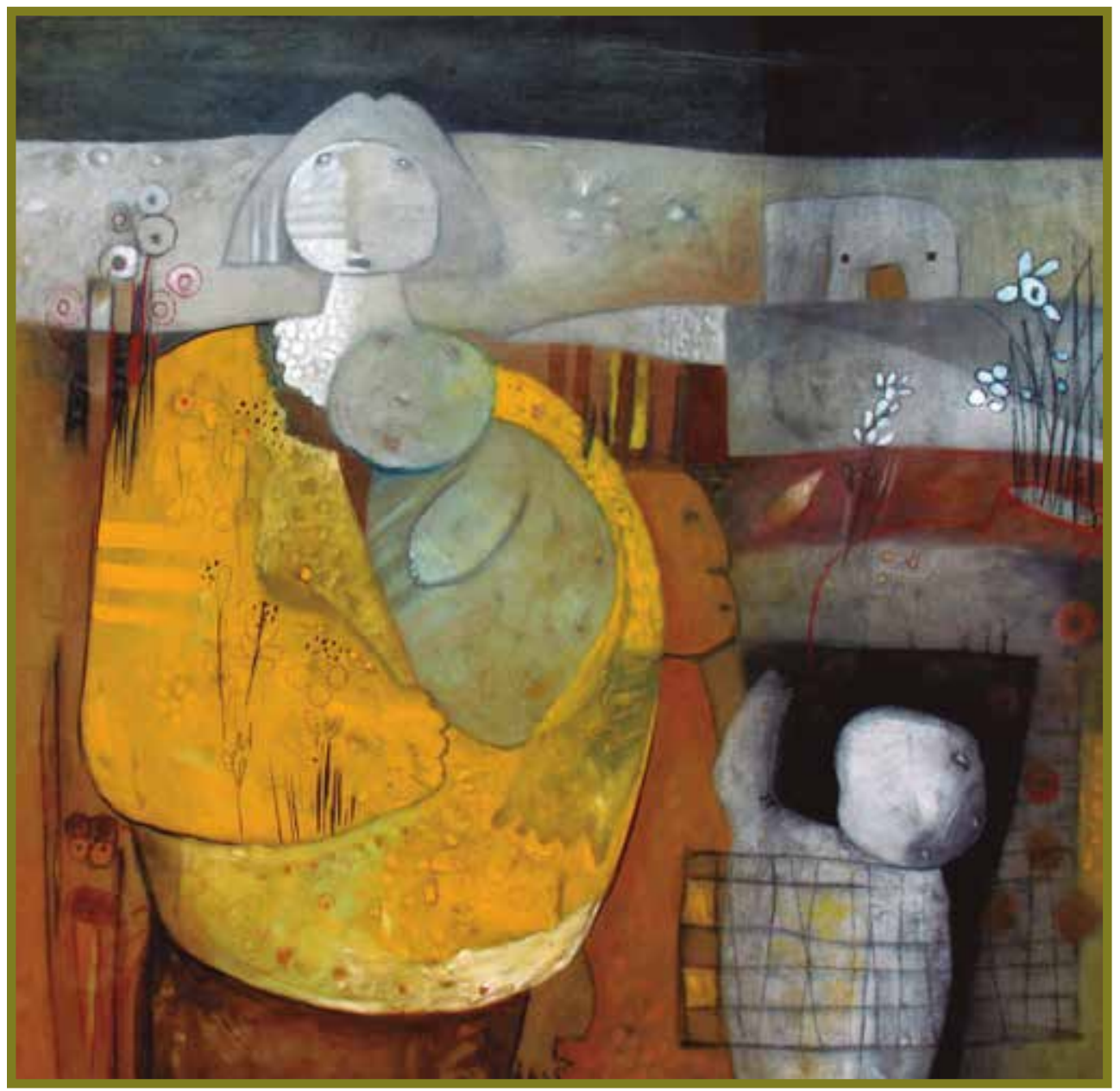

Mi madre me criaba entre las retamas. Pintura. Juan Carlos Nañake. 